REVISTA X, Curitiba, volume 14, n.6,p. 24-43, 2019.

\title{
VISÕES DE LINGUAGEM DE ALUNOS-PROFESSORES DE LÍNGUA INGLESA E O LETRAMENTO CRÍTICO
}

\author{
Language Views of Pre-Service Teachers of English and Critical Literacy
}

Juliane D'ALMAS (UNESPAR) ${ }^{1}$

\begin{abstract}
RESUMO: O objetivo deste trabalho é analisar e descrever as visões de linguagem de alunos-professores de Língua Inglesa. A pesquisa tem como contexto alunos do segundo ano de um curso de Letras Inglês que responderam a uma atividade de leitura que requeria seu posicionamento como leitor e professor. Uma das perguntas do exercício na posição de professor exigia que o aluno expressasse sua visão de linguagem para uma suposta aula de leitura em inglês. São as respostas para esta pergunta que analisamos neste artigo, com base nos preceitos de teorias tais como o Letramento Crítico, Consciência Crítica da Linguagem e Leitura Crítica (FREIRE, 1978; FAIRCLOUGH, 1992; 1995), as quais foram base para toda a atividade proposta. A análise dos dados mostra que grande parte dos estudantes ofereceu respostas insuficientes para tal pergunta, pois apresentam dificuldades em conceituar o que é uma visão de linguagem e como ela se aplica em uma atividade de sala de aula. Por outro lado, dentre aqueles que responderam à questão sem maiores conflitos, a maioria vê linguagem principalmente como decodificação e meio de comunicação, enquanto a minoria compreende linguagem como uma ferramenta de empoderamento e dissipação de ideologias.
\end{abstract}

PALAVRAS-CHAVE: Formação de professores; Letramento Crítico; Linguagem; Língua Inglesa.

\begin{abstract}
This article aims at analyzing and describing the language views of preservice teachers of English. The context of this research is formed by students from the second year of a Letras course, who answered a reading activity which required their positions as readers and teachers. One of the questions from this exercise in the reader position demanded that the student expressed his/her language view for a purported English reading class. The answers for these questions are the data for the analysis in this article, based on assumptions from theories such as Critical Literacy, Critical Language Awareness and Critical Reading (FREIRE, 1978; FAIRCLOUGH, 1992; 1995), which were the basis of the whole activity. The data analysis shows that most of the students offered insufficient answers to the question, since they presented difficulties to conceptualize what a language views and how it is applied to a classroom activity. On the other hand, among those who answered the question with no conflicts, most of them see language mainly as a decoding process and a means of communication, while few of them comprehend language as a means of empowerment and ideology dissipation.
\end{abstract}

KEYWORDS: Critical Literacy; English; Language; Teacher education.

\footnotetext{
${ }^{1}$ Professora Adjunta no Curso de Letras Inglês na Universidade Estadual do Paraná (UNESPAR) - Campus Apucarana. Doutora em Estudos da Linguagem pela Universidade Estadual de Londrina (UEL). julianedalmas@gmail.com
} 


\section{INTRODUÇÃO}

Este artigo propõe-se a analisar as visões de linguagem de licenciandos de Língua Inglesa a partir de uma atividade respondida por eles no segundo ano do curso de Letras a fim de identificar se suas respostas se afiliavam aos conceitos de Letramento Crítico (doravante LC) que permeavam todo o exercício. Os dados desta investigação foram gerados por meio de atividade sobre leitura (APÊNDICE A), na qual os acadêmicos deveriam respondê-la primeiramente na posição de professor e, depois, na posição de aluno.

Sabemos que a linguagem constitui parte essencial daquilo que o professor trabalha em sala de aula. No caso do professor de línguas, ela é instrumento e objeto de ensino e aprendizagem, pois é por meio dela que o trabalho docente se estabelece. Sendo assim, é indispensável para o professor que ele saiba a qual visão de linguagem se afilia, ou seja, como ele entende o que é língua/linguagem e como esse entendimento interfere no seu modo de ensinar. Isto é, ele pode, por exemplo, compreender linguagem como um meio de comunicação, usada para troca de mensagens entre interlocutor e receptor mantendo-se neutra nesse processo, ou ainda definir linguagem como instrumento de poder, capaz de manipular discursos, com a propriedade de manter (ou desfazer) relações de poder e estruturas sociais, dissipar ideologias, entre outras definições que serão explicadas adiante.

Apresentamos, portanto, algumas visões de língua/linguagem que são estudadas no campo da Linguística Aplicada e enfatizamos a perspectiva do LC, uma vez que ela faz parte de visões de linguagem mais atuais. Além disso, a atividade analisada se baseava nesta perspectiva e tínhamos o intuito de saber se o aluno responderia criticamente as questões, tanto na posição de estudante, quanto na posição de professor, quando teria que imaginar como utilizar as imagens apresentadas em uma aula de leitura em língua inglesa.

Sendo assim, o LC aqui é base de toda a pesquisa, pois acreditamos que esta perspectiva é compatível com uma visão que entende a linguagem como uma prática social (FAIRCLOUGH, 2001), perpassada por ideologias e estruturas sociais que as compõem, fazendo dela uma forma de manipulação, de propagação de discursos e de modos de pensar e agir para o benefício de um grupo social ou indivíduo que normalmente está ou precisa manter sua posição de poder. Ademais, o LC é uma perspectiva de ensino e aprendizagem amplamente necessária e útil no século XXI, pois discursos chegam a nós a todo momento através de diversas fontes e em questão de segundos. É primordial ensinarmos a futuros professores e a discentes da educação básica o poder que a linguagem assume em vários contextos para que eles possam reconhecer as informações que recebem, formar suas próprias 
opiniões e serem capazes de agir na sociedade como indivíduos ativos em busca de mudanças (caso assim desejem).

Este estudo divide-se em cinco partes, tais quais: uma breve explanação sobre as diferentes visões de linguagem que permeiam o campo da linguística, outra síntese sobre o termo LC dentro da literatura do campo de ensino de línguas, seguido pela metodologia da pesquisa, onde elencamos os passos realizados durante o processo de geração e análise dos dados, sendo a própria análise e seus resultados a quarta parte do texto, que é finalizado pelas considerações finais.

Vale acrescentar que este artigo não tem a intenção de julgar as respostas dos alunos participantes (mesmo que toda interpretação seja subjetiva e carregada de ideologias), mas sim de tentar compreender a quais visões de linguagem estes se afiliam e as razões das respostas fornecidas. Ressaltamos que este trabalho não dá fim à discussão que iremos iniciar e, por isso, muito ainda poderá ser acrescentado às nossas considerações, uma vez que diferentes pesquisadores podem interpretar os dados com outras lentes.

\section{VISÕES DE LINGUAGEM ${ }^{2}$}

Diferentes visões de linguagem marcam o campo da Linguística desde as tradições gramaticais dos gregos, passando pelos pioneiros estudos de Ferdinand de Saussure e seu “Curso de Linguística Geral” em 1916. A partir de tal publicação, o linguista distinguiu língua de linguagem, considerando a primeira um fenômeno individual, e o sistema linguístico como um fenômeno social. Ainda assim, segundo o estudioso, os elementos linguísticos são abstratos, estáveis e imutáveis, restando para o sujeito apenas a tarefa de reproduzi-los. Isto é, a linguagem é apenas um meio de comunicação, uma maneira de disseminar informação a partir de um falante para um receptor por meio de uma mensagem, enquanto a língua é somente um instrumento que torna possível o uso da linguagem pelos indivíduos. Em suma, Saussure (2006) parte do pressuposto de que não é possível um conhecimento científico da linguagem humana, por isso, se limita a estudar apenas o seu aparato técnico, ou seja, a língua e seus componentes, entre eles a fonologia, fonemas e signos, descartando atenção sobre a fala - o exercício subjetivo da linguagem.

Bakhtin (1997), por outro lado, interessa-se justamente pela fala, pelo modo como as pessoas fazem uso da linguagem em seu dia a dia, desse modo, a linguagem, a seu ver, faz

\footnotetext{
${ }^{2}$ Para deixar claro ao leitor, esclarecemos que utilizamos as palavras abordagem e perspectiva como sinônimos e entendemos que as visões de linguagem estão intimamente ligadas com os modos como a linguagem/língua é ensinada, ou seja, as abordagens ou perspectivas as quais o professor se afilia para compreender a linguagem.
} 
parte de um conjunto de fenômenos históricos e sociais, sendo, portanto, ideológica. Nesse sentido, o indivíduo se constitui através da linguagem e é constituído por ela e ambos se tornam inseparáveis. De acordo com o autor, o sujeito é formado por palavras e discursos de outros que o circundam durante toda sua vida, isto é, o indivíduo está constantemente inserido em uma fronteira daquilo que é seu e aquilo que é do outro. Por este motivo, Bakhtin defende que a linguagem está permeada por relações de poder, ideologias, heterogeneidades e subjetividade.

Alguns anos mais tarde, Fairclough (2001) busca explicar as relações entre linguagem e poder e dá especial atenção ao discurso que, para ele, é o uso da linguagem de maneira socialmente determinada. Para este autor, primeiramente, a linguagem é parte de uma sociedade e não de alguém externo a ela. Em segundo lugar Fairclough defende que a linguagem é um processo social. Em terceiro, a linguagem é, para ele, um processo socialmente condicionado pelas outras partes da sociedade (ambiente social, instituições sociais e a sociedade como um todo). Sendo assim, o linguista pontua que:

não existe uma relação externa 'entre' linguagem e sociedade, mas uma relação interna e dialética. Linguagem é parte da sociedade, fenômenos linguísticos são fenômenos sociais de um tipo especial e os fenômenos sociais são (em parte) fenômenos linguísticos. Fenômenos linguísticos são sociais no sentido de que quando as pessoas falam ou ouvem ou escrevem ou leem, elas fazem isso de maneiras determinadas socialmente e que tem efeitos sociais. [...] Os fenômenos sociais são linguísticos, por outro lado, no sentido de que a atividade de linguagem que acontece em contextos sociais (como toda a atividade linguística acontece) não é meramente um reflexo ou expressão de processos sociais e práticas, ela é parte desses processos e práticas. (FAIRCLOUGH, 2001, p. 23)

Isto posto, Fairclough dá atenção especial às questões de ideologia e relações de poder permeadas nos discursos contemporâneos e como o uso de determinada linguagem, as escolhas feitas pelo falante e o modo como esse discurso é disseminado causam impactos nas vidas, nas estruturas sociais e nas concepções de quem lê, ouve ou vê determinada linguagem em uso em um texto, propaganda, outdoor, etc. Ele acredita que o exercício de poder na sociedade moderna está cada vez mais sendo atingido por meio da ideologia, e mais particularmente por meio de trabalhos ideológicos da linguagem, sendo a natureza ideológica

3 ... there is not an external relationship 'between' language and society, but an internal and dialectical relationship. Language is part of society; linguistics phenomena are social phenomena of a special sort, and social phenomena are (in part) linguistic phenomena. Linguistic phenomena are social in the sense that whenever people speak or listen or write or read, they do so in ways which are determined socially and have social effects. [...] Social phenomena are linguistic, on the other hand, in the sense that the language activity which goes on in social contexts (as all language activity does) is not merely a reflection or expression of social processes and practices, it is a part of those processes and practices. (FAIRCLOUGH, 2001, p. 23). 
da linguagem um dos principais temas a serem pesquisados na ciência social moderna. $\mathrm{O}$ linguista acredita que as pessoas precisam estar conscientes dos efeitos da linguagem sobre si, e de como certos pressupostos podem ser ideologicamente moldados por relações de poder. Tal consciência pretendida por Fairclough pode ir ainda mais longe, pois o objetivo maior é que essa consciência dos efeitos da linguagem permita o desenvolvimento da capacidade do ser humano de transformar o que outros seres humanos têm criado. Ou seja, a resistência e a mudança efetiva dependem das pessoas envolvidas com uma consciência crítica da dominação, ao contrário de apenas experienciá-las.

Complementando as ideias acima, Mattos (2017) afirma que quando falamos sobre ensino de línguas, podemos identificar quatro visões diferentes que entendem a língua e a linguagem de maneiras também distintas, sendo elas: a abordagem psicolinguística, a abordagem comunicativa, a abordagem sociocultural e a abordagem crítica. A abordagem psicolinguística vê a língua como um conjunto de palavras e estruturas governadas por regras e princípios específicos que são armazenados nas mentes de aprendizes individuais. Já para a perspectiva comunicativa a língua serve para comunicação e construção de significados, suas regras são aprendidas por meio do contato e uso da língua. $\mathrm{Na}$ abordagem sociocultural a língua também é compreendida como ferramenta para construção de significados, contudo, esses significados se constroem em situações, lugares e ocasiões específicos e entre indivíduos específicos. Por fim, na abordagem crítica a língua é moldada por ideologias e forças sociais, culturais e políticas abrangentes que ao mesmo tempo que auxiliam no empoderamento de alguns sujeitos, também são capazes de oprimir outros.

Estas são apenas algumas visões de linguagem que podemos encontrar na literatura. Na seção seguinte, focaremos na abordagem do Letramento Crítico e na perspectiva crítica de linguagem, pois este era o foco do grupo de pesquisa que conduziu esta investigação.

\section{LETRAMENTO CRÍTICO}

Segundo Cervetti, Pardales e Damico (2001) o termo Letramento Crítico tem suas raízes tanto na teoria crítica social, como na pedagogia crítica de Paulo Freire (1978), que a partir de suas obras, incluindo a mundialmente reconhecida Pedagogia do Oprimido, pregava por uma educação libertária na qual professores e alunos fossem vistos mediante o mesmo patamar, onde o procedimento de ensino e aprendizagem fosse tratado como uma troca de informações e não uma transmissão delas. O educador também prezava por uma educação problematizadora, a qual ensinasse seus alunos a enxergar a relação entre seus problemas individuais e o contexto social maior em que estavam inseridos. Freire (1978) propunha o 
ensino de uma leitura crítica de mundo e não somente de palavras, ou seja, ler as entrelinhas dos discursos que chegam a nós a todo momento. Segundo Cervetti et al. (2001) a pedagogia crítica vê linguagem e letramento como mecanismos para a reconstrução social, pois os significados da linguagem são sempre contestados (e nunca dados), e por isso estão relacionados com lutas sociais derivadas da posse heterogênea de conhecimento, de poder, de status e de recursos materiais. Isto posto, os autores supracitados definem que o objetivo central da pedagogia crítica é o desenvolvimento de consciência crítica (CERVETTI; PARDALES; DAMICO, 2001, p. 7).

Outro autor que também se preocupava com o desenvolvimento de consciência crítica da linguagem foi o britânico Norman Fairclough (1992; 1995; 2001). Para o linguista, é extremamente necessário que uma educação linguística esteja focada em componentes críticos, pois se assim não estiver, esta estará falhando em sua responsabilidade para com os aprendizes:

As pessoas não podem ser cidadãos efetivos em uma sociedade democrática se a educação deles os priva de consciência crítica dos elementos chave dentro do ambiente físico ou social. Se nós estamos comprometidos com a educação estabelecendo recursos para a cidadania, as práticas de consciência crítica da linguagem dos discursos de uma comunidade é um direito. (1992, p. 6$)^{4}$.

Ainda nesse sentido, Fairclough se interessa especificamente pela relação da linguagem no discurso, com a intenção de propagação de relações de poder e ideologias. Por isso, ele advoga por uma educação que possibilite os indivíduos a desvendar tais relações de poder e agir, caso queiram, para modificar as situações de opressão em que vivem. Suas obras tiveram grande impacto para se compreender melhor a perspectiva do LC, mesmo que este termo pouco apareça em seus escritos.

Antes de comentar mais sobre teorias de LC, devemos esclarecer que entendemos que a maior diferença entre pedagogia crítica e LC está nos seus objetivos finais, ou seja, a pedagogia crítica foca no desenvolvimento de consciência e pensamento crítico, enquanto o LC pretende que, a partir desse desenvolvimento de consciência crítica da linguagem, os indivíduos possam agir para transformar uma realidade, caso assim desejem (D’ALMAS, 2011; 2016).

\footnotetext{
${ }^{4}$ People cannot be effective citizens in a democratic society if their education cuts them off from critical consciousness of key elements within their physical or social environment. If we are committed to education establishing resources for citizenship, critical awareness of the language practices of one's speech community is an entitlement. (FAIRCLOUGH, 1992, p. 6).
} 
REVISTA X, Curitiba, volume 14 , n.6,p. 24-43, 2019.

Com o passar dos anos, outros estudiosos se interessaram pelas abordagens/perspectivas críticas de ensino e publicaram pesquisas e teorias sobre LC. Alguns deles (TAGLIEBER, 2000; JANKS, 2000; COMBER, 2001; ANDREOTTI; SOUZA, 2006; JORDÃO, 2007; WIELEWICKI, 2007; EDMUNDO, 2013) voltaram-se para os aspectos emancipadores desta perspectiva de ensino, procurando estabelecer ligação entre leitura crítica e consciência crítica da linguagem em busca de agência e empoderamento a fim de propor transformações. Segundo Brahim (2007) esses autores concretizaram o uso de LC por meio das práticas sociais críticas. Já outros autores (WALLACE, 1992; HEBERLE, 2000; LUKE, 2000; 2004; MORRELL, 2002; LUKE; DOOLEY, 2011; JORDÃO; FOGAÇA, 2012) parecem interpretar o LC como uma maneira de propor leitura crítica em sala de aula, focando principalmente em meios de revelar relações de poder e ideologias através da leitura de textos. Nesse sentido, Brahim (2007) novamente distingue que essa segunda proposta de uso do LC foca mais no engajamento crítico com e através dos textos. Por exemplo, Luke e Dooley (2011) definem LC como sendo "o uso de textos para analisar e transformar relações de poder cultural, social e política", pois eles acreditam que:

[...] o desenvolvimento igualitário e a aquisição de linguagem e letramento por comunidades e estudantes historicamente marginalizadas e voltado ao uso de textos em uma diversidade de meios de comunicação para analisar, criticar, representar e alterar estruturas de conhecimento assimétricas e relações sociais de escola e sociedade.5 (LUKE; DOOLEY, 2011, p. 1).

Já para Jordão (2007), LC é mais do que apenas leitura de textos. É desenvolver o espírito crítico e, acima de tudo, tentar lutar contra as estruturas dominantes. Para isso, o indivíduo "deve ver-se como parte integral do mundo, ou seja, como agente na produção de significados e na construção da própria realidade que se está tentando transformar” (p. 27).

Apesar de algumas diferenças em como os autores definem LC e o foco que dão para seus estudos, Green (2001) concluiu que, basicamente, a literatura sobre o tema reúne os mesmos princípios comuns, os quais evocam a necessidade de "reposicionar os estudantes como pesquisadores da linguagem, respeitando as práticas de letramento cultural da minoria e problematizando textos públicos e de sala de aula" (p. 7).

Segundo Lewinson, Flint e Sluys (2002) a literatura sobre LC estabelece basicamente 4 maiores focos, sendo eles: 1) romper o lugar comum; 2) interrogar vozes múltiplas; 3) focar

\footnotetext{
5 " [...] the equitable development and acquisition of language and literacy by historically marginalized communities and students, and towards the use of texts in a range of communications media to analyse, critique, represent and alter inequitable knowledge structures and social relations of school and society". (LUKE; DOOLEY, 2011, p. 1).
} 
em questões sócio-políticas; 4) agir e promover justiça social. Ou seja, pode-se tanto olhar apenas para as questões de linguagem e perceber o objetivo de seus usos, ou ir além e agir a fim de transformar e propor mudanças para que a sociedade seja um pouco mais justa.

No cenário educacional brasileiro, o LC encontra-se estipulado como abordagem de ensino-aprendizagem tanto de língua materna, como de língua estrangeira nos Parâmetros Curriculares Nacionais (PCN) e nas Orientações Curriculares para o Ensino Médio (OCEM). Mesmo que tais documentos não tragam explicitamente a expressão letramento crítico, é possível perceber ideias que se coadunam com os pressupostos desta abordagem durante a leitura dos mesmos. De acordo com o último documento:

(...) a necessidade da capacidade crítica se fortalece não apenas como ferramenta de seleção daquilo que é útil e de interesse ao interlocutor, em meio à massa de informação a qual passou a ser exposto, mas também como ferramenta para a interação na sociedade, para a participação na produção da linguagem dessa sociedade e para a construção de sentidos dessa linguagem (BRASIL, 2006, p. 97).

A partir desta citação, fica claro que a consciência crítica da linguagem é elemento essencial na atualidade, onde nos deparamos diariamente com as famosas fake news e precisamos fazer seleção cuidadosa daquilo que lemos, ouvimos e falamos. Dessa maneira, faz-se necessário então que um curso de formação inicial de professores apresente a seus alunos componentes críticos de ensino e aprendizagem, uma vez que em seus futuros contextos de trabalho, os professores em formação lidarão com currículos e documentos que regem a educação, precisarão compreendê-los e fazer suas escolhas sobre como irão trabalhar em sala de aula. Não preconizamos aqui que o LC é a única (ou a melhor) perspectiva de ensino e aprendizagem. Entretanto, ele faz parte de uma gama de opções, e, além disso, está inserido nos documentos oficiais que regem a educação deste país. Por isso, é importante conhecê-lo e principalmente entender como essa perspectiva compreende o que é linguagem/língua.

\section{DESENHO DA PESQUISA}

Esta investigação contou com a participação de 21 alunos do curso de Letras Inglês da Universidade Estadual de Londrina (UEL), sendo que 11 frequentavam o turno vespertino e 10 estavam matriculados no período noturno.

Os estudantes que participaram desta pesquisa estavam inseridos no segundo ano do curso anteriormente mencionado e as atividades foram aplicadas no início do ano letivo na 
REVISTA X, Curitiba, volume 14 , n.6,p. 24-43, 2019.

disciplina de Leitura em Língua Inglesa, onde os mesmos teriam contato com várias perspectivas sobre o ensino de leitura, incluindo o LC.

A geração dos dados deu-se por meio de duas atividades (APÊNDICES A e B) que objetivavam checar como os alunos se posicionavam perante a leitura de duas imagens (APÊNDICES C e D). A diferença entre as atividades consistia na maneira em como iriam realizá-las, pois, primeiramente, o aluno respondia as questões na posição de professor, como se estivesse usando aquelas imagens para uma aula de língua inglesa, enquanto na segunda atividade era requerido que eles respondessem as perguntas como leitores, supondo que estivessem fazendo a atividade na posição de estudantes. $\mathrm{O}$ instrumento foi produzido em língua inglesa, mas o acadêmico tinha liberdade para respondê-lo em português caso sentisse dificuldade na língua estrangeira.

Para que fique claro ao leitor, as atividades foram produzidas pela professora responsável pela disciplina e as imagens foram capturadas pela própria docente em viagem internacional; são imagens encontradas em transportes públicos da cidade de Londres, na Inglaterra. A atividade foi conduzida na aula de Leitura em Língua Inglesa, porém, a análise das respostas ficou por conta do grupo de pesquisa conduzido pela mesma docente que lecionava a disciplina. Desse grupo de pesquisa faziam parte alunos de pós-graduação que eram orientados pela docente em questão. Cada pós-graduando ficou responsável por analisar uma questão da referida atividade e compartilhar com os colegas do grupo.

Sendo assim, neste estudo analisamos somente a resposta de uma pergunta referente à primeira atividade realizada (pergunta 2.3 destacada no APÊNDICE A), a qual tinha como objetivo compreender qual seria a visão de linguagem adotada pelos acadêmicos, agora na posição de professor, caso utilizassem as figuras mencionadas em uma atividade de leitura em língua inglesa.

Para a análise utilizamos o método indutivo-dedutivo que faz parte do processo de análise paradigmática e sintagmática (APS) (REIS, 2018), no qual lemos as respostas da primeira turma (vespertino) e procuramos estabelecer categorias nas quais estas pudessem ser agrupadas por afinidade de conteúdo. Os dados seguintes - da turma do período noturno foram sendo agrupados nas categorias já estabelecidas ou demandaram a criação de novas categorias.

Como procedimentos éticos, os estudantes assinaram um Termo de Consentimento Livre e Esclarecido, o qual explicava que suas repostas poderiam ser utilizadas em trabalhos futuros. Neste estudo, analisamos apenas uma das perguntas da atividade, como explicado 
anteriormente, todavia, caso o leitor se interesse pelo tema e queira saber mais sobre a análise da atividade como um todo, indicamos a investigação de Lopes (2013).

\section{ANÁLISE}

A fim de elucidarmos melhor a análise dos dados deste estudo produzimos dois quadros que sintetizam as respostas fornecidas pelos alunos à pergunta sobre qual seria a visão de linguagem adotada para a atividade de leitura que proporiam a seus alunos em uma sala de aula de língua inglesa na qual imaginaram ser o público alvo de tal ação (os estudantes citavam anteriormente qual seria a série em que a atividade poderia ser aplicada). Os quadros foram divididos em: sujeito (identificação do participante sob as siglas de $\mathrm{V}$ para aluno do vespertino e $\mathrm{N}$ para aluno do período noturno), visão de linguagem (resposta dada pelo aluno) e categoria de análise (nome da categoria a qual a resposta pertence). Além disso, após algumas categorias, segue uma explicação das possíveis razões para cada resposta fornecida, principalmente no caso das não-respostas. Salientamos que optamos por manter as respostas originais dadas pelos estudantes, mesmo que essas apresentassem desvios gramaticais em língua portuguesa ou em língua inglesa.

Seguem, portanto as respostas dos acadêmicos à pergunta: "Suponha que você irá utilizar as figuras A e B em uma aula de leitura. Por favor, escreva: 2.3 sua visão de linguagem na aula de leitura. ${ }^{6}$

Quadro 1: Sujeitos, respostas e categorias de análise dos alunos do período vespertino.

\begin{tabular}{|c|c|c|}
\hline \multicolumn{3}{|c|}{ DADOS VESPERTINO } \\
\hline Participante & Visão de linguagem & Categoria de análise \\
\hline V1 & $\begin{array}{l}\text { "I hope to make my students see the language as } \\
\text { way to act in the world". }\end{array}$ & $\begin{array}{l}\text { Linguagem como forma de } \\
\text { empoderamento. }\end{array}$ \\
\hline $\mathrm{V} 2$ & $\begin{array}{l}\text { "Identificação do tipo de linguagem usada, } \\
\text { imagem, lugar, e pra quem esse tipo de } \\
\text { informação e direcionado". }\end{array}$ & Linguagem como decodificação. \\
\hline V3 & $\begin{array}{l}\text { "I believe in the reading class language means: } \\
\text { practice the language we are learning, not only } \\
\text { texts, but picture, sounds, etc". }\end{array}$ & $\begin{array}{l}\text { Não resposta } \text { (V3 acredita que } \\
\text { linguagem é prática, fluência no } \\
\text { idioma). }\end{array}$ \\
\hline V4 & Não respondeu. & Em branco. \\
\hline V5 & "Students able to have a little discussion about & Não resposta (V5 parece ter descrito o \\
\hline
\end{tabular}

\footnotetext{
${ }^{6}$ Suppose that you are going to use pictures A and B in a reading class. Please, write: 2.3 . your view of language in the reading class:
} 


\begin{tabular}{|c|c|c|}
\hline & your travel". & $\begin{array}{l}\text { objetivo da aula e não a visão de } \\
\text { linguagem). }\end{array}$ \\
\hline V6 & $\begin{array}{l}\text { "Students may be aware of daily law } \\
\text { vocabulary". }\end{array}$ & $\begin{array}{l}\text { Não resposta (V6 parece ter descrito o } \\
\text { objetivo do texto e não a visão de } \\
\text { linguagem). }\end{array}$ \\
\hline V7 & $\begin{array}{l}\text { "Leitura é uma das melhores forma que passa } \\
\text { ajudar os estudante em relação à língua } \\
\text { estrangeira ou segunda língua porem só com a } \\
\text { leitura que passamos conhecer a oralidade tanto } \\
\text { quanto a escrita". }\end{array}$ & $\begin{array}{l}\text { Não resposta (V7 escreveu sobre a } \\
\text { importância da leitura e não sobre a } \\
\text { visão de linguagem). }\end{array}$ \\
\hline V8 & $\begin{array}{l}\text { "My view of language in the reading class is that } \\
\text { I will able to read any kind of texts, even I don't } \\
\text { know a lot about what the text about, learn } \\
\text { vocabulary too and context". }\end{array}$ & $\begin{array}{l}\text { Não resposta (V8 considera visão de } \\
\text { linguagem o mesmo que leitura tipo } \\
\text { scanning). }\end{array}$ \\
\hline V9 & $\begin{array}{l}\text { "Language as a communicative resource and a } \\
\text { way to understand the world". }\end{array}$ & $\begin{array}{l}\text { Linguagem como meio de comunicação. } \\
\text { Linguagem como forma de } \\
\text { empoderamento. }\end{array}$ \\
\hline V10 & $\begin{array}{l}\text { "The language in the reading class need to be } \\
\text { understandable and to contain the subject they } \\
\text { are supposed having". }\end{array}$ & $\begin{array}{l}\text { Não resposta (V10 respondeu como se a } \\
\text { pergunta fosse para dizer que tipo de } \\
\text { linguagem seria usada na atividade). }\end{array}$ \\
\hline V11 & $\begin{array}{l}\text { "I'd like to work with critical reading, teach the } \\
\text { students about how important is analyze the text } \\
\text { because words hides purposes and ideas". }\end{array}$ & $\begin{array}{l}\text { Não resposta (a leitura crítica pressupõe } \\
\text { uma visão de linguagem em que } \\
\text { nenhum traço da linguagem é neutro, } \\
\text { mas dizer que gostaria de trabalhar com } \\
\text { leitura crítica não é o mesmo que } \\
\text { responder qual visão de linguagem a } \\
\text { aula de leitura adotaria). }\end{array}$ \\
\hline
\end{tabular}

Fonte: A autora

Quadro 2: Sujeitos, respostas e categorias de análise dos alunos do período noturno.

\begin{tabular}{|l|l|l|}
\hline \multicolumn{3}{|c|}{ DADOS NOTURNO } \\
\hline Participante & \multicolumn{1}{|c|}{ Visão de linguagem } & \multicolumn{1}{c|}{ Categoria de análise } \\
\hline N1 & $\begin{array}{l}\text { "to make the students think or act freely about } \\
\text { the subject, then the reading of pictures A and B } \\
\text { are a request and not a order". }\end{array}$ & $\begin{array}{l}\text { Não resposta (N1 parece descrever o } \\
\text { objetivo da atividade e não a visão de } \\
\text { linguagem adotada). }\end{array}$ \\
\hline N2 & $\begin{array}{l}\text { "Language can be a way of getting the meaning } \\
\text { from the text and the context". }\end{array}$ & $\begin{array}{l}\text { Linguagem como decodificação. } \\
\text { N3 }\end{array}$ \\
\hline language, but also about our lives experiences". & $\begin{array}{l}\text { lexts an activity to teach them about the } \\
\text { texture o aluno concordava ou não com o }\end{array}$ \\
\hline
\end{tabular}


REVISTA X, Curitiba, volume 14, n.6,p.24-43, 2019.

\begin{tabular}{|c|c|c|}
\hline N4 & $\begin{array}{l}\text { "“View of language" can be everything students } \\
\text { have to interpretate to get the activity right". }\end{array}$ & Linguagem vista como interpretação. \\
\hline N5 & $\begin{array}{l}\text { "Linguagem é qualquer coisa que possibilite a } \\
\text { comunicação". }\end{array}$ & $\begin{array}{l}\text { Linguagem como meio de } \\
\text { comunicação. }\end{array}$ \\
\hline N6 & $\begin{array}{l}\text { "Uma boa leitura em sala de aula consiste em } \\
\text { uma boa interpretação, no caso das figuras como } \\
\text { eles já estão acostumados a vê-las talvez eles } \\
\text { tenham uma melhor interpretação". }\end{array}$ & Linguagem vista como interpretação. \\
\hline N7 & $\begin{array}{l}\text { "It's important for them to face pictures like } \\
\text { those the teacher have to organize the subjects } \\
\text { and choose the most useful. They have to have a } \\
\text { cool understanding". }\end{array}$ & $\begin{array}{l}\text { Não resposta (N7 parece não ter } \\
\text { compreendido a pergunta). }\end{array}$ \\
\hline N8 & $\begin{array}{l}\text { "My view of language is my understanding of } \\
\text { these situations". }\end{array}$ & $\begin{array}{l}\text { Não resposta (o exercício não pretendia } \\
\text { saber a visão de linguagem do } \\
\text { professor, mas sim a visão de } \\
\text { linguagem que seria adotada na aula de } \\
\text { leitura). }\end{array}$ \\
\hline N9 & "I agree with the picture". & $\begin{array}{l}\text { Não resposta (a pergunta não era sobre } \\
\text { se o aluno concordava ou não com o } \\
\text { texto). }\end{array}$ \\
\hline N10 & "A code used to express knowledge". & Linguagem como decodificação. \\
\hline
\end{tabular}

Fonte: A autora

As respostas transcritas nos quadros sugerem que os alunos-professores de língua inglesa possuem dificuldade em descrever uma visão de linguagem que guie sua possível aula de leitura. Esta consideração é comprovada pelo fato de que entre 21 alunos, obtivemos 12 não-respostas, ou seja, respostas que não possuem relação alguma com a pergunta feita. Além disso, obtivemos também uma resposta em branco, o que pode demonstrar mais ainda a falta de conhecimento, a dificuldade do aluno sobre o tópico ou sua falta de engajamento com a atividade.

Das respostas válidas, podemos distinguir quatro visões diferentes, as quais são, ao mesmo tempo, as categorias criadas por meio da APS: linguagem como forma de empoderamento, linguagem como decodificação, linguagem como meio de comunicação, linguagem vista como interpretação.

Em linguagem como empoderamento, temos as respostas de dois alunos-professores, V1 e V9. O primeiro descreve a linguagem como não neutra, capaz de assumir diversos significados dependendo do contexto onde é elaborada e disseminada, sendo assim, 
linguagem passa a ser uma ferramenta de manipulação e tratá-la como um instrumento de empoderamento realça seu caráter de emancipação e agência. Sendo assim, este acadêmico traz em sua resposta fortes traços da pedagogia crítica e do LC, pois entende a linguagem como um modo de agir no mundo, isto é, para ele está claro que a linguagem faz parte da sociedade, como diz Fairclough (2001).

Já V9, na segunda parte de sua resposta, considera que a linguagem pode ser uma forma de compreender mais do que palavras, mas também o que está ao redor do indivíduo. Por isso, para ele, a linguagem ainda é tida como uma ferramenta de entendimento do mundo. Esta resposta do participante V9 parece se conectar com as teorias do LC e da pedagogia crítica, pois, para Freire (1978), por exemplo, a linguagem nos auxilia a entender o mundo, o qual deve ser 'lido' pelas pessoas por meio de uma leitura crítica. Ainda segundo Cervetti, Pardales e Damico (2001) a leitura, dentro do LC, é um meio de vir a conhecer o mundo e também as palavras, com possibilidade de transformação social.

Três alunos-professores (V2, N2 e N10) descrevem linguagem como decodificação, isto é, para eles, linguagem serve para ler, compreender e analisar textos escritos. Ademais, para isso, é preciso ensinar o estudante a procurar por pistas inseridas no texto, como imagens, notas de rodapé, cabeçalho, título, manchete, etc. Neste tipo de visão, a linguagem é apenas um instrumento para decodificação de ideias e informações que o leitor precisa entender, pois sempre há uma autoridade do autor do texto (ANDREOTTI; SOUZA, 2006). Logo, tais cognições dos acadêmicos se relacionam com a visão saussuriana de língua como código e estrutura.

Para dois estudantes (V9 e N5), linguagem é vista como meio de comunicação, ou seja, nesse tipo de visão, a linguagem é somente um mecanismo de propagação de ideias, servindo assim como um elo de comunicação entre alguém que irá enunciar uma mensagem e outro indivíduo que será o receptor desta, de maneira neutra e imparcial. Quando entendemos linguagem como meio de comunicação temos, novamente, uma visão tradicional de língua, onde é preciso levar em consideração normas sociais, por exemplo, regras gramaticais para que a mensagem seja transmitida com sucesso, uma vez que este tipo de visão compreende a língua como fixa e neutra (ANDREOTTI; SOUZA, 2006).

Por fim, dois alunos-professores (N4 e N6) entendem linguagem vista como interpretação, ao passo que consideram primordial que a leitura de um texto seja feita de maneira a encontrar uma interpretação correta. Para estes alunos, a linguagem de um texto precisa ser decifrada para que se alcance uma interpretação certa daquilo que se leu, como se 
fosse possível e necessário compreender exatamente o que o autor quis dizer. Aqui temos uma visão de linguagem tradicional, onde a língua é vista como código e tem a intenção de traduzir ou representar a realidade (ANDREOTTI; SOUZA, 2006).

Em suma, podemos compreender que apenas dois alunos (V1 e V9) possuíam uma visão de linguagem que vai além das superfícies. Primeiramente, V1 por entender que a linguagem tem poder e é capaz de auxiliar no empoderamento de sujeitos a fim de que estes vejam como os discursos agem na sociedade. E V9 por compreender a linguagem como modo de entender o mundo, ou seja, a linguagem faz parte dos discursos que compõem as práticas sociais e o indivíduo deve ser capaz de ler o mundo através desses discursos, da linguagem. Não podemos, no entanto, considerar as respostas dos outros alunos mais ou menos 'corretas' apenas porque a autora deste artigo e o grupo de pesquisa do qual participa se afilia ao modo como o LC compreende a linguagem. Entendemos que os outros posicionamentos ainda estão marcados pelas definições de linguagem de Saussure, e consideramos que esta perspectiva pode ser um pouco reducionista para os dias de hoje, pois uma visão de linguagem tradicional não dá conta de formar um cidadão crítico. Ademais, acreditamos que o aluno desenvolverá com o tempo conceitos e definições de linguagem que mais se assemelhem ao seu trabalho em sala de aula. Podemos, ainda, supor que tais respostas são derivadas da educação a que estes estudantes foram expostos em seu percurso durante a educação básica, visto que, no momento da geração de dados, os alunos estavam iniciando suas atividades no segundo ano do ensino superior e ainda não tinham entrado em contato com os pressupostos do LC ou outras perspectivas de leitura.

\section{CONSIDERAÇÕES FINAIS}

O presente trabalho objetivou analisar e descrever as visões de linguagem de alunosprofessores de inglês a partir de suas respostas para uma atividade que esperava compreender como os discentes utilizariam imagens em uma suposta aula de leitura em língua inglesa e qual seria a visão de linguagem adotada durante este exercício.

A partir das 21 respostas coletadas, obtivemos oito respostas, 11 não-respostas e uma resposta em branco. Das oito respostas válidas, criamos quatro categorias de análise que resumiam, segundo as interpretações desta pesquisadora, as visões de linguagem dos alunos, sendo elas: linguagem como forma de empoderamento, linguagem como decodificação, linguagem como meio de comunicação, linguagem como ferramenta de compreensão, linguagem vista como interpretação. 
REVISTA X, Curitiba, volume 14 , n.6,p. 24-43, 2019.

Durante a análise, percebemos que apenas dois alunos-professores entendiam linguagem como instrumento de empoderamento e como maneira de entender o mundo, tendo assim uma visão diferente de seus colegas, os quais, em sua maioria, compreendem linguagem como maneira de interpretar textos ou um elo de comunicação, basicamente.

Tendo em vista os pressupostos do LC como base da atividade proposta, consideramos, portanto, que esta perspectiva de ensino e aprendizagem ainda está muito distante da realidade dos alunos que ingressam no ensino superior, pois, de certa forma, nem mesmo grande parte dos professores que os ensinaram durante o ensino básico compreendem o que esta perspectiva aborda (CORADIM, 2008). Os resultados também nos fazem perceber que os acadêmicos, apesar de terem estudado a perspectiva do LC na disciplina na qual a atividade foi aplicada, eles não conseguiram pensar que a atividade em questão poderia ser utilizada para trabalhar com LC.

Linguagem é também interpretação, decodificação e comunicação, entretanto, essas visões têm sido criticadas ultimamente, pois, não devemos nos limitar à visão de linguagem tradicional, em que língua é neutra, fixa e busca representar a realidade (ANDREOTTI; SOUZA, 2006). Ao contrário, futuros professores devem se comprometer com perspectivas de ensino, tais como o LC, que entendem a linguagem como mecanismo de interpretação profunda de textos e discursos, compreensão ampla de mundo(s) em todas suas instâncias e decodificação abrangente de tudo que se vê, ouve, lê e fala.

\section{REFERÊNCIAS}

ANDREOTTI, V.; SOUZA, L. M. T. M. de. Uma Breve Introdução ao Letramento Crítico na Educação em Línguas Estrangeiras. Brasília, 2006.

BAKHTIN, M. Estética da Criação Verbal. $2^{a}$ ed. São Paulo: Martins Fontes, 1997.

BRASIL. Parâmetros Curriculares Nacionais para o Ensino Médio, 2000.

BRASIL. Ministério da Educação. Secretaria de Educação Básica. Orientações Curriculares para o Ensino Médio: linguagens, códigos e suas tecnologias. Brasília, 2006, v. 1.

CERVETTI, G.; PARDALES, M. J.; DAMICO, J. S. A Tale of Differences: comparing the traditions, perspectives, and educational goals of critical reading and critical literacy. 2001.

COMBER, B. Negotiating Critical Literacies in Classrooms. New Jersey: Lawrence Erlbaum Associates, Inc. 2001. 
CORADIM, J. N. Leitura Crítica e Letramento Crítico: idealizações, desejos ou (im)possibilidades? 2008. 123f. Dissertação (Mestrado em Estudos da Linguagem) Universidade Estadual de Londrina, Londrina.

D'ALMAS, J. Leitura crítica: um estudo da aprendizagem e alunos-professores de inglês. 2011. 152f. Dissertação (Mestrado em Estudos da Linguagem) - Universidade Estadual de Londrina, Londrina.

D'ALMAS, J. Da passividade à agência: desenvolvimento de professoras como resultado de empoderamento. 2016. 307f. Tese (Doutorado em Estudos da Linguagem) - Universidade Estadual de Londrina, Londrina.

EDMUNDO, E. S. G.; Letramento Crítico no Ensino de Inglês na Escola Pública. Planos e Práticas nas Tramas da Pesquisa. Campinas: Pontes Editores, 2013.

FAIRCLOUGH, N. Critical Language Awareness. London: Longman, 1992.

FAIRCLOUGH, N. Critical Discourse Analysis. London: Longman, 1995.

FAIRCLOUGH, N. Language and Power. $2^{\mathrm{a}}$ ed. London: Longman, 2001.

FREIRE, P. Pedagogia do Oprimido. 5 ${ }^{\text {a }}$ ed. Rio de Janeiro: Paz e Terra, 1978.

GREEN, P. Critical Literacy Revisited. In: FERHING, H.; GREEN, P. (Eds.). Critical Literacy: a collection of articles from the Australian literacy educators' association. Newark: International Reading Association, 2001. p. 7-13.

HEBERLE, V. M. Critical reading: integrating principles of critical discourse analysis and gender studies. Ilha do Desterro, Florianópolis, n. 38, p. 115-138, jan./jul. 2000.

JANKS, H. Domination, Access, Diversity and Design: a synthesis for critical literacy education. In: Educational Review. v. 52, n. 2, 2000. p. 175-186.

JORDÃO, C. M. O que todos sabem... ou não: letramento crítico e questionamento conceitual. Revista Crop, dez. 2007.

LEWISON, M.; FLINT, A. S.; SLUYS, K. V. Taking on Critical Literacy: The Journey of Newcomers and Novices. In: Language and Arts, v. 79, n. 5, 2002. p. 382-392.

LOPES, L. M. Leituras de professores de inglês em formação por meio de atividade embasada no letramento crítico. 2013. 103f. Dissertação de Mestrado (Mestrado em Estudos da Linguagem) - Universidade Estadual de Londrina, Londrina.

LUKE, A. Critical literacy in Australia. Journal of Adolescent and Adult Literacy, v. 43, 2000. p. 1-19.

LUKE, A. Two takes on the critical. In: NORTON, B.; TOOHEY, K. (Eds.). Critical Pedagogies and Language Learning. Cambridge University Press, 2004. 
LUKE, A.; DOOLEY, K. Critical literacy and second language learning. In: Hinkel (Ed.) Handbook of Research in Second Language Teaching and Learning. v. II. New York: Routledge, 2011.

MATTOS, A. M. A. Problematizando a Formação de Professores no Brasil: possibilidades e perspectivas. Minicurso. IV Congresso Nacional de Estudos Linguísticos - CONEL. Vitória, 2017.

MORRELL, E. Toward a critical pedagogy of popular culture: literacy development among urban youth. Journal of Adolescent and Adult Literacy, Sep. 2002. p. 72-77.

REIS, S. Análise paradigmática e sintagmática em pesquisa qualitativa com dados de linguagem humana. Signum: Estudos da Linguagem. v. 21, n. 2. Ago. 2018. p. 147-171.

SAUSSURE, F. Curso de Linguística Geral. 27ª ed. São Paulo: Editora Cultrix, 2006.

TAGLIEBER, L. K. Critical reading and critical thinking: the state of the art. Ilha do Desterro, Florianópolis, n. 38, p. 15-37. jan./jul. 2000.

WALLACE, C. Critical literacy awareness in the EFL Classroom. In: FAIRCLOUGH, N. (Ed.). Critical Language Awareness. London: Longman, 1992. p. 59-92.

WIELEWICKI, V. H. G. Reading foreign literature at university level in Brazil: developing critical readers. In: ANDREOTTI, V.; SOUZA, L. M. T. M. de (Orgs.). Critical Literacy: theories and practices. v. 1:1, jul. 2007. p. 52-62. 
APÊNDICE A - Instrumento de Coleta de Dados

Atividade de leitura na posição de professor

Answer the questions that follow (either in English or in Portuguese):

Starting time:

1. Could pictures A and B be used as a resource material for a reading class?

( ) yes ( ) no

2. Justify your answer to question 1:

Suppose that you are going to use pictures A and B in a reading class. Please, write:

2.1. the grade of target students:

2.2. the objective(s) of your reading class:

2.3. your view of language in the reading class:

2.4. the tasks for students to do in the reading activity/activities:

2.5. the type(s) of knowledge demanded by the task(s)? (please, give examples).

2.6. Write questions and/or propositions for your student/reader to answer:

2.7. Write your criteria to evaluate students' learning in your reading activity:

3. How difficult was it to answer this questionnaire? Why?

a.( ) very easy b.( ) easy c.( ) not so easy d.( ) difficult e.( ) very difficult

4. Would you like to receive an analytical feedback on your answers?

( ) yes, my e-mail address is:

( ) no

Finishing time:

APÊNDICE B - Instrumento de Coleta de Dados

Atividade de leitura na posição de leitor

Answer the questions that follow (either in English or in Portuguese):

Starting time:

1. What do pictures A and B depict? Please, give evidence from the text which supports your answer.

2. Where and when were the pictures probably taken? Please, add evidence from the text which supports your answer.

3. Who do you think is the author of the messages contained in the pictures?

4. Who are the messages addressed to?

5. Who is explicit and who is implicit in each message? 
R E V IS T A X, Curitiba, volume 14, n.6, p. 24-43, 2019.

\begin{tabular}{|l|l|}
\hline Message 1 (Picture 1) & Message 2 (Picture 2) \\
\hline & \\
& \\
\hline
\end{tabular}

6. What is the communicative objective of each message?

\begin{tabular}{|l|l|}
\hline Message 1 (Picture 1) & Message 2 (Picture 2) \\
\hline & \\
& \\
\hline
\end{tabular}

7. Could any of these messages be more communicatively effective than the other? Explain your answer.

8. Who benefits from the messages?

Message 1:

Message 2:

9. Find the types of verbs, determiners, and predicates in each message:

\begin{tabular}{|l|l|l|}
\hline & $\begin{array}{l}\text { Message 1 } \\
\text { (Picture 1) }\end{array}$ & $\begin{array}{l}\text { Message 2 } \\
\text { (Picture 2) }\end{array}$ \\
\hline $\begin{array}{l}\text { Types of verbs } \\
\text { (Action, Mental, } \\
\text { Stative) }\end{array}$ & & \\
\hline $\begin{array}{l}\text { Determiners } \\
\text { (pronouns) }\end{array}$ & & \\
\hline $\begin{array}{l}\text { Predicates } \\
\text { (adjectives) }\end{array}$ & & \\
\hline
\end{tabular}

10. Comparing, the two messages, which one is more direct? Which one is more subtle? Explain your answers.

11. In your city, are there messages whose purposes are similar to those of Pictures 1 and 2 ? If your answer is affirmative, in what aspects, if any, could they be improved? Why?

12. How difficult was it to answer this questionnaire? Why?

a.( ) very easy b.( ) easy c.( ) not so easy d.( ) difficult e.( ) very difficult

13. Would you like to receive an analytical feedback on your answers?

( ) yes, my e-mail address is:

( ) no

Finishing time: 
REVISTA X, Curitiba, volume 14, n.6,p.24-43, 2019.

APÊNDICE C - Instrumento de Coleta de Dados

Figura A

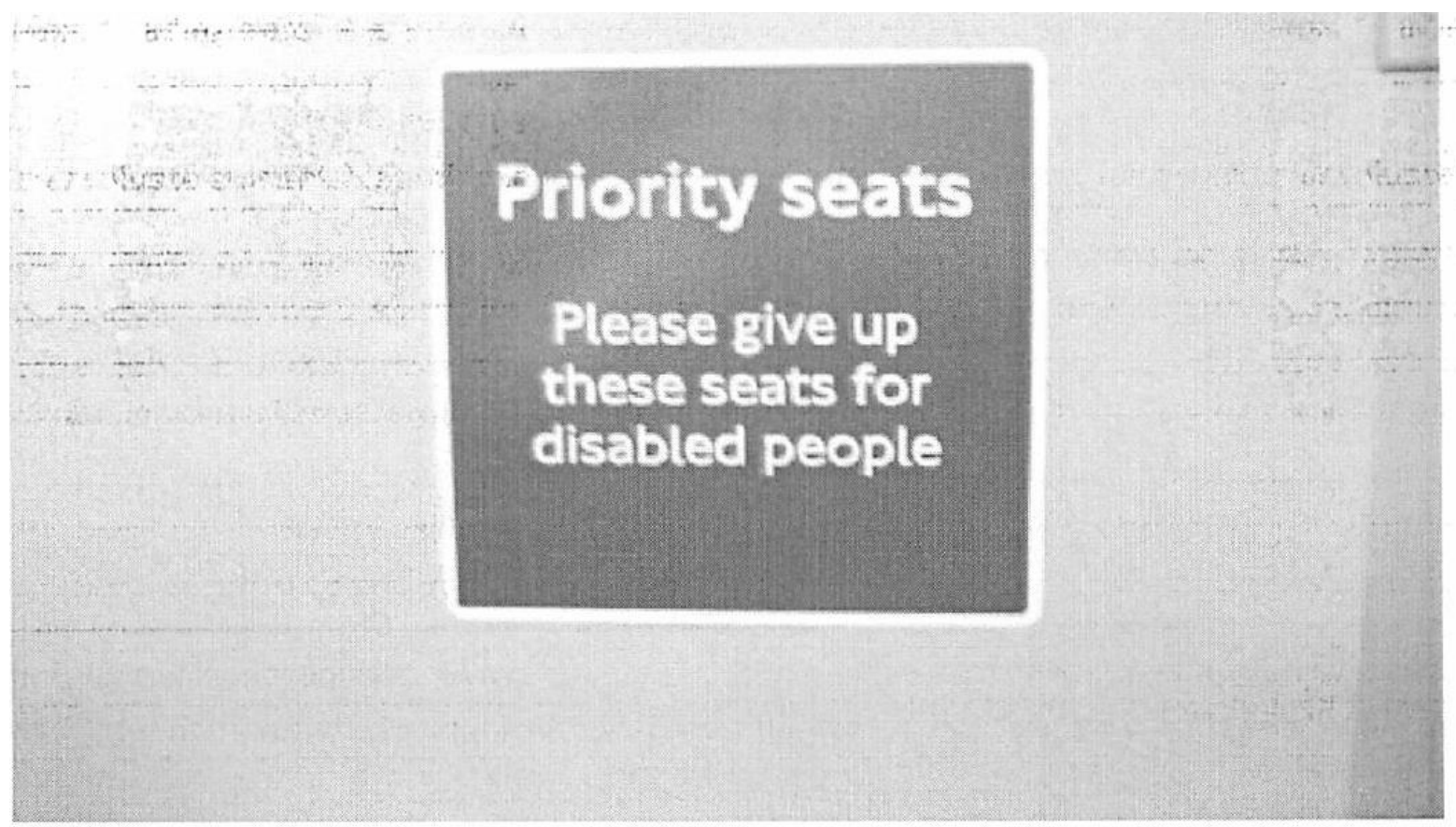

Picture A

APÊNDICE D - Instrumento de Coleta de Dados

Figura B

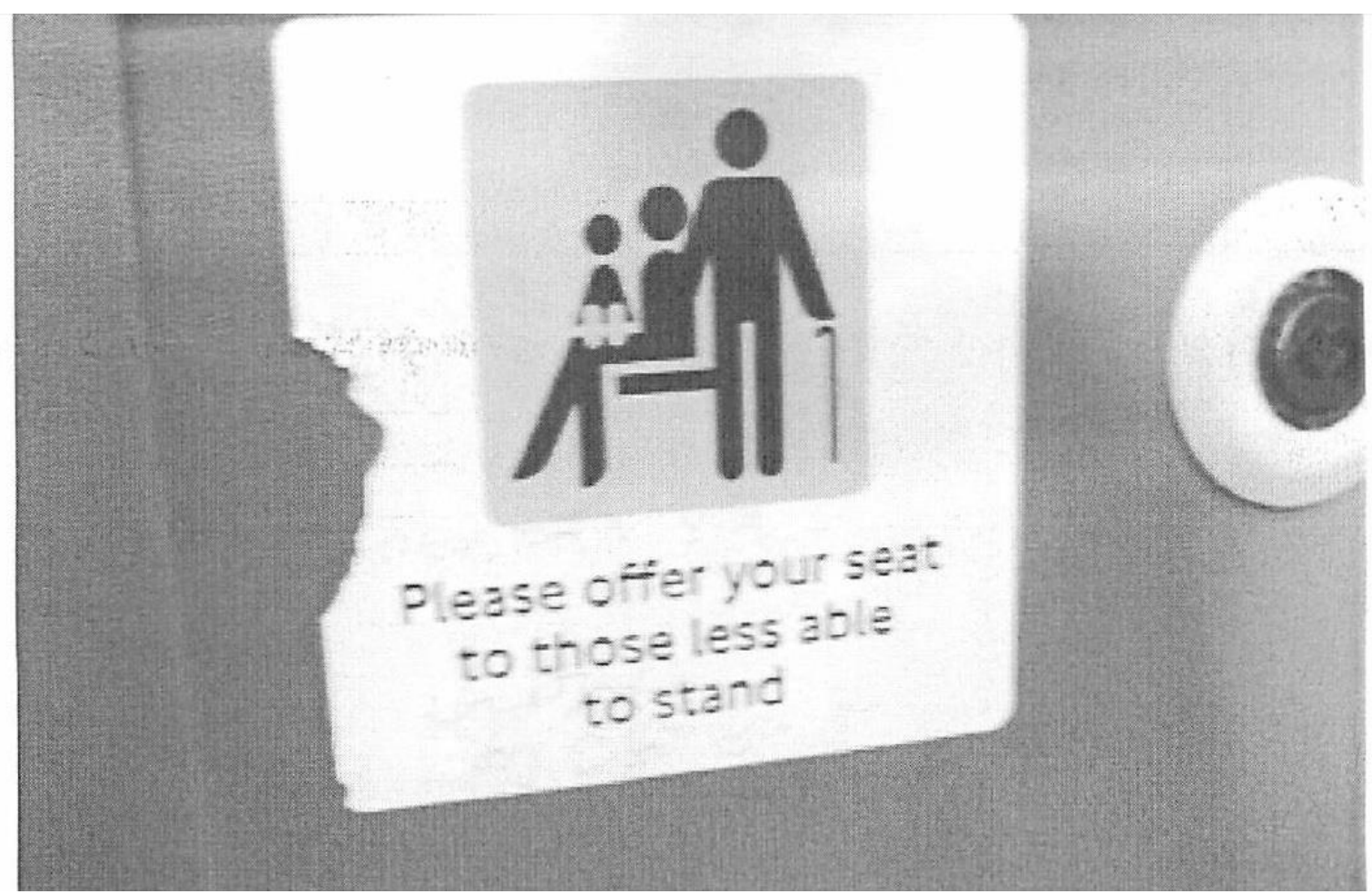

